\title{
Investigating Synchromodality from a Supply Chain Perspective ${ }^{1}$
}

\author{
Chuanwen Dong $^{\mathrm{a},{ }^{*}}$, Robert Boute $^{\mathrm{b}}$, Alan McKinnon ${ }^{\mathrm{a}}$, and Marc Verelst ${ }^{\mathrm{c}}$ \\ ${ }^{a}$ Kuehne Logistics University, Hamburg 20457, Germany \\ ${ }^{b}$ Technology and Operations Management, Vlerick Business School, Leuven 3000, Belgium; and Research \\ Center for Operations Management, KU Leuven, Leuven 3000, Belgium \\ ${ }^{c}$ Supply Network Innovation Center, Strombeek-bever 1853, Belgium
}

\begin{abstract}
Greater use of multimodal transportation can substantially improve the environmental performance of freight transportation. Despite strenuous efforts by public policy-makers to alter the freight modal split, most companies still rely heavily on road transportation, and modal shifts to rail and water have remained modest at best. In this paper we argue that this is partly the result of a failure to take a holistic supply chain view of the modal shift process. Synchromodality provides a framework within which shippers can manage their supply chains more flexibly to increase the potential for shifting mode. On the basis of a literature review, we broaden the conventional focus of multimodal transportation to give it a supply chain dimension, and propose the concept of 'Synchromodality from a Supply Chain Perspective' (SSCP). Using a case study we show that when the supply chain impacts are taken into account, it is possible to significantly increase the share of intermodal rail transportation within a corridor, without necessarily increasing total logistics cost or reducing the service level. In this way the environmental impact of freight activities can be significantly reduced.
\end{abstract}

Keywords: modal split, synchromodality, supply chain, review, stochastic model, application

\footnotetext{
${ }^{1}$ To appear in Transportation Research Part D: Transport and Environment

${ }^{*}$ Corresponding author, Tel: +49 40328707302.

Email addresses: chuanwen.dong@the-klu.org (C. Dong), robert.boute@vlerick.com (R. Boute), alan.mckinnon@the-klu.org (A. McKinnon), marc.verelst@edu.vlerick.com (M. Verelst).
} 


\section{Introduction}

Between now and 2050 we will have to reduce our greenhouse gas (GHG) emissions dramatically to keep our environment sustainable. According to calculations from the Intergovernmental Panel on Climate Change (IPCC) (2014), annual GHG emissions need to be reduced by $40-70 \%$ between 2010 and 2050, for us to have $50 \%$ chance of keeping the increase in average global temperature staying within $2^{\circ} \mathrm{C}$ by 2100 . The Paris Accord, agreed at the COP21 conference in December 2015, committed the 195 participating countries to keeping this average temperature increase 'well below $2^{\circ} \mathrm{C}$ by $2100^{\prime}$, putting added pressure on them to cut GHG emissions (European Commission, 2015).

All industrial sectors except transportation have been steadily reducing their GHG emissions. In the U.S., GHG emissions linked to transportation have increased by 17\% since 1990 (U.S. Environmental Protection Agency, 2014). In the EU-28 (the 28 state members of the European Union), the transportation sector increased its relative share in total GHG emissions from 15\% to 22\% between 1990 and 2013 (EUROSTAT, 2015a). The freight share of total transportation emissions is expected to rise from $42 \%$ in 2010 to $60 \%$ in 2050 (OECD/ITF, 2015), making the freight transportation one of the hardest sectors to decarbonize (Guerin et al., 2014).

Fundamental changes are needed in the transportation sector in order to reverse the growth in GHG emissions. According to Schipper et al. (2000) and IPCC (2014), this will involve the application of a broad range of measures, falling into four categories: 1 ) activity (reducing the demand for transportation), 2) structure (shifting freight to lower carbon modes), 3) intensity (improving its energy efficiency) and 4) fuel (switching to lower carbon energy sources). By far the most frequently mentioned freight decarbonization measure in the Intended Nationally Determined Contribution (INDC) documents submitted to COP21 was modal shift, i.e. transferring freight to lower carbon transportation modes (Gota, 2016). According to European Environment Agency (2013), $\mathrm{CO}_{2}$ emissions per tonne-kilometer from railways and inland waterways are about 3.5 and 5.0 times lower than those from road freight transportation. Shifting freight from road to these alternative modes can therefore be one of the most important means of decarbonizing logistics (Holguin-Veras et al. (2008), Winebrake et al. (2008), McKinnon (2008), Hoen et al. (2013))

Modal shift has long been 'seen by policy makers and politicians as the most promising way of easing the environmental and congestion problems associated with goods movement' (McKinnon, 2015). There has been over 50 years of research on the factors influencing companies' choice of freight transportation mode (e.g. Bayliss and Edwards (1970), Jeffs and Hills (1990)), and the use of public policy to alter the allocation of freight between modes. The case for government intervention has been underpinned by the belief that, at a macro-level, the freight modal split is economically and / or environmentally sub-optimal. This suboptimality has resulted partly from a failure to internalize the environmental costs of freight transportation 
modes, but also from differences in the regulatory and pricing regimes of the various modes and deficiencies in corporate modal choice behavior. Much emphasis has been placed on the relative pricing of the alternative modes and numerous attempts have been made to quantify cross-modal price elasticities (De Jong et al. (2010), De Jong (2013)). Comparative freight rates, however, are only one of many factors influencing the freight modal split at both micro- and macro-levels. Other criteria, such as transit time, reliability, accessibility, flexibility and security, are also important determinants of modal selection.

In Europe, strenuous efforts over many years by national governments and the EU to shift freight from road to rail and water have been unsuccessful. Between 1995 and 2013, road's share of total tonne-kms increased, rail's share declined and that of inland waterways remained fairly stable (Figure 1) (EUROSTAT, 2015b). A recent report from the European Court of Auditors (2016) confirms that rail's share of the European freight market has declined since 2011 despite the fact that approximately 28 billion Euros of financial support was injected into railway projects across the EU over the period 2007-2013. Therefore innovations are urgently needed to promote and revive modal shift as a freight policy option.

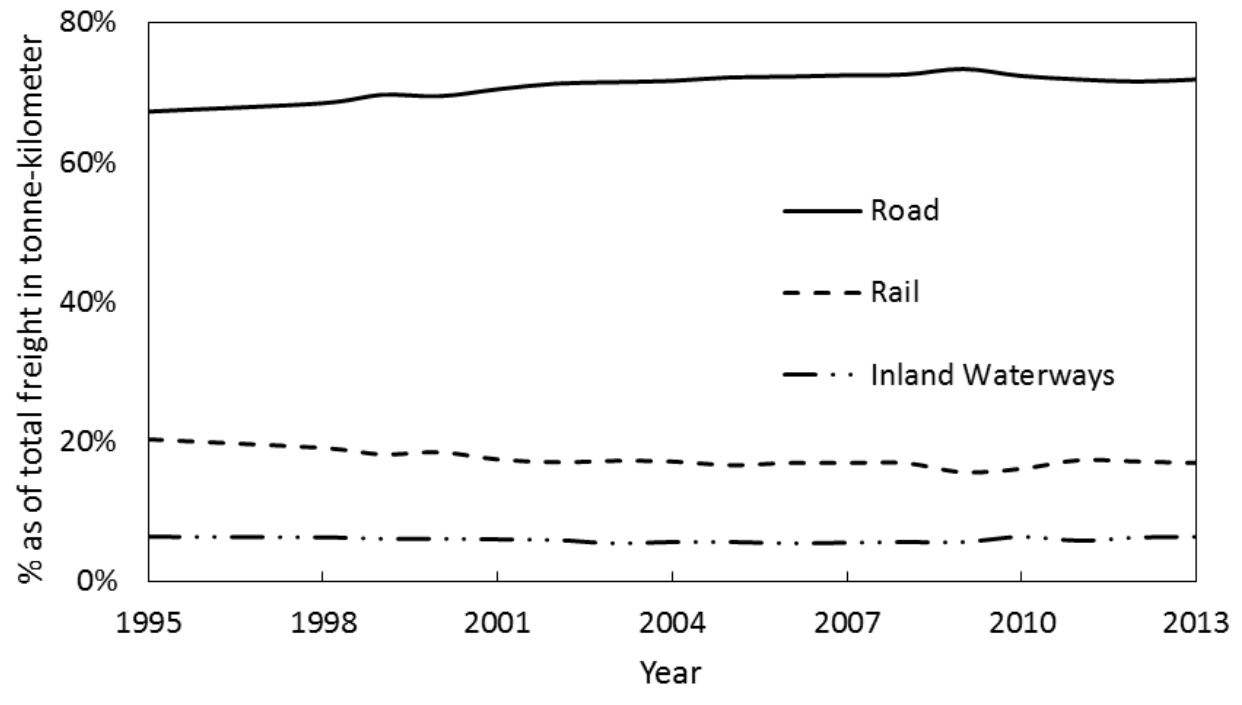

Figure 1: The freight modal split ratio in EU-28 (EUROSTAT, 2015b)

One of the reasons for the modal split being so difficult to change is that many stakeholders have not been taking adequate account of the overall supply chain impact of multimodal transportation. Trains or barges are in general cheaper and greener, but they lack flexibility in delivery quantity, frequency and scheduling. As a consequence, logistics managers tend to perceive a straight shift from trucks to trains and barges as likely to have a negative impact on the supply chain. More specifically, in the absence of any associated adjustment to supply chain processes, a shift from trucks to trains and barges often leads to increases in inventory. As rail and inland waterway services are generally slower and less frequent than the equivalent road trips, in-transit inventories and stock levels might be higher at both ends of the journey. Trains and 
barges also require large and stable shipment volumes in order to be cost-efficient, making it difficult for them to cater for flows that are subject to widely fluctuating demand.

The end-to-end impact of the modal shift requires a change in the logistical decision-making process. Freight modal choice is, after all, a part of the supply chain strategy and needs to be jointly optimized with other supply chain activities, like inventory management and customer service levels. This involves the shipper more directly in the process and puts some onus to alter their schedules to accommodate changes in transportation mode.

Some researchers have already analyzed transportation as a part of the supply chain. Woodburn (2003) conducted a survey of 137 British shippers and observed that managers' perception of rail as possibly impairing supply chain performance is a barrier to this mode increasing its market share. Eng-Larsson and Kohn (2012) analyzed six case studies and found that shippers make modal shift decisions in a different way than Logistics Service Providers (LSPs) because they need to consider trade-offs and synergies across the supply chain as a whole. This previous research is mainly qualitative in nature and needs to be complemented by quantitative studies and best practices case studies.

In this paper we aim to fill this research gap and contribute to the existing literature on the following two points: First, this study broadens the focus of multimodal research from the transportation system to the supply chain. We review the development of multimodal transportation and the recent evolution of the socalled synchromodality concept. We argue that this concept needs to be more deeply embedded in supply chain management and propose the expression 'Synchromodality from a Supply Chain Perspective' (SSCP) to reflect this. This is discussed in section 2. Secondly, this study provides a quantitative demonstration using a company case study to show how modal shift can be enabled when the supply chain impact is taken into account. In section 3 we show that by following a SSCP approach, a company can markedly increase the share of intermodal rail transportation within a particular transportation corridor without sacrificing either logistical efficiency or service quality. Section 3 also assesses the environmental impact of this modal shift using a case study of a company and discusses the role of a carbon tax herein. Section 4 summarizes the paper and indicates further SSCP research opportunities.

\section{The Conceptual Framework of SSCP}

Companies adopting a multimodal strategy have to decide the optimum allocation of their freight among different modes. The development of intermodal transportation has expanded the range of modal options available. By allowing companies to combine different modes in various ways in the course of a single journey it has further complicated the modal choice decision. The advent of synchromodality has made this decision even more complex, but also increased the potential for companies to make greater use on 
transportation modes besides road. The next section reviews the evolution of modal split research from multimodality and intermodality to synchromodality.

\subsection{Multimodal, intermodal, and synchromodal transportation}

The general concept of combining the use of several modes for any transportation at strategic, tactical, or operational level is generally described as 'multimodal transportation'. Different modes can be used for different types of commodity, movements of distance, and requirements of services. A company's relative dependence on different modes can also vary significantly between countries reflecting, among other things, differences in the national freight market, the relative density of modal infrastructures and government transportation policy. Over the years numerous studies have been conducted on the topic and detailed literature reviews can be found in articles of McGinnis (1989), Meixell and Norbis (2008), Reis et al. (2013), SteadieSeifi et al. (2014), Reis (2015).

Multimodality should be distinguished from 'intermodality'. Although there is a lack of consensus on the definition of intermodality (Bontekoning et al., 2004), it is widely accepted that it refers to a sequence of different transportation modes used on a single journey, and very likely, a unitized module is used along this freight journey: for example, a container is 'pre-hauled' by truck from the sender to an intermodal terminal, trunk-hauled by train or ship to another intermodal terminal, and then 'post-hauled' by truck to the receiver. The same sealed, modular unit (e.g. a container) travels from origin to destination (Macharis and Bontekoning, 2004). Modular consignments are channeled through intermodal terminals where they are transshipped between modes in large numbers to exploit the scale economies of rail and water-borne transportation (European Commission, 1997). The literature on intermodality has been reviewed by, among others, Macharis and Bontekoning (2004), Bontekoning et al. (2004), Crainic and Kim (2007), SteadieSeifi et al. (2014), and Reis (2015).

Recently synchromodality (or 'synchromodal transportation') has emerged as the next conceptual development linked to multimodal transportation (e.g., Verweij (2011), Roth et al. (2013), Tavasszy et al. (2015)). In one of its first explanations, Verweij (2011) characterized synchromodality as the ability to switch freely between transportation modes at particular times while a consignment is in transit. For example, a container that was originally planned to be shipped via intermodal rail transportation might be switched to direct trucking at certain terminals, because of real-time constraints or a desire to improve utilization / cut costs. The necessary level of flexibility for switching between different transportation modes requires efficient and responsive coordination of the schedules of the available transportation modes. In this way, synchromodality offers the potential to switch mode at several nodes on the route, while meeting cost and service level requirements. 
Behdani et al. (2016) and Tavasszy et al. (2015) describe the distinctive feature of synchromodality as 'horizontal integration' of freight transportation planning, which allows for parallel usage of different transportation modes from the origin to the destination. Freight flows on a particular route, possibly satisfying the same order, are then split between different modes. This contrasts with 'vertical integration' of different modes which is inherent in a door-to-door intermodal movement. Figure 2 illustrates both concepts. Intermodal transportation comprises sequential usage of multiple transportation modes. synchromodal transportation, on the other hand, permits their simultaneous usage, and furthermore, one of these modes could be an intermodal service. Tavasszy et al., (2015) define synchromodality as 'synchronized intermodality'. When Logistics Service Providers (LSPs) implement the horizontal integration of different transportation modes and internally synchronize flows, they can do so without consulting shippers. The shippers then make a-modal or 'modal-free' bookings, giving LSPs discretion to use multiple modes on schedules that meet the shippers' service level requirement at the agreed costs (Gorris et al., 2011).
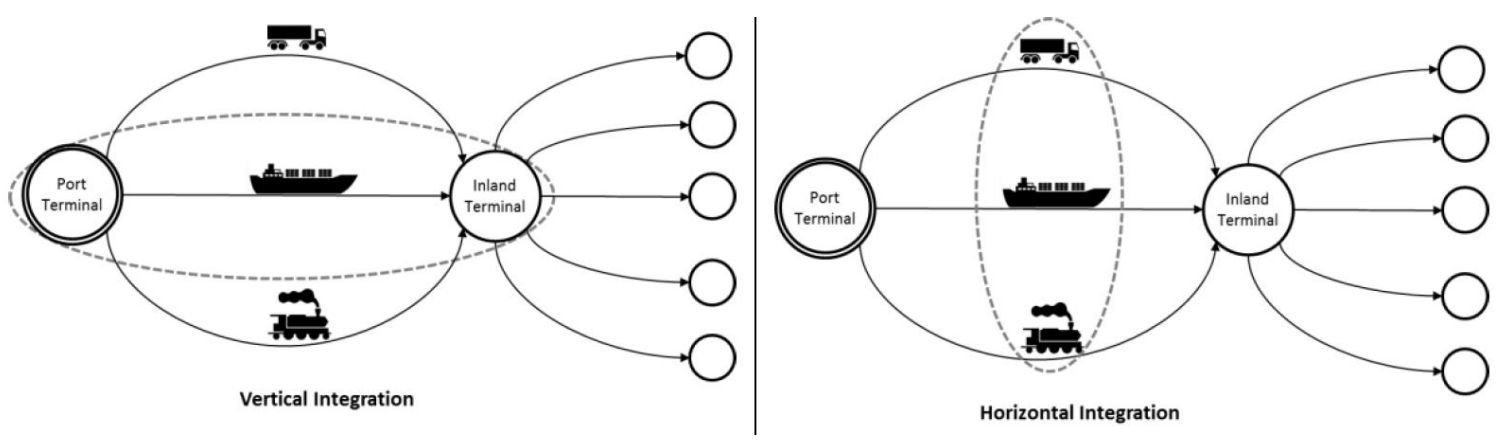

Figure 2: The vertical and horizontal integration of freight transportation planning (Behdani et al. (2016), Tavasszy, et al. (2015))

Groothedde et al. (2005) show how this 'horizontal integration' can be operationalized. In their case study, they model parallel usage of two transportation modes: a premium, fast and flexible transportation mode (direct trucking), and a relatively inexpensive, slow and inflexible transport mode (intermodal). The two transportation modes are synchronized in such a way that the stable part of the freight demand is carried by intermodal transportation, and the variable peaks are accommodated by direct trucking.

\subsection{Review of the current literature on synchromodality}

While multimodal and intermodal transportation have been extensively reviewed in the literature, synchromodality is relatively new. We therefore reviewed the recent literature on synchromodality to get a better understanding of the current state-of-the-art. The keywords 'synchromodality' and 'synchromodal transportation' were inserted into the following databases: Emerald Insight, Google Scholar, IEEE Xplore, JSTOR, OECD (Organisation for Economic Co-operation and Development) library, Springer Link and Web of Science. In total 24 articles written in English were found that elaborate on the concept of synchromodality: 
nine journal articles, seven conference proceedings, three book chapters, four white papers and one working paper. We are aware that there may exist additional reports or articles in other languages. In Table 1 we list these 24 articles, together with their definition of the synchromodality concept and its advantages as described in their work.

Several key points emerged from the literature:

1. Synchromodality research is still in its early stage. The number of publications however is growing as shown in Figure 3.

2. The majority of the studies are exploratory and qualitative in nature, which is not surprising for an emerging concept. The first quantitative study was found only in 2015. In 2016 three more quantitative studies were published. The emergence of quantitative studies indicates a deepening understanding of the concept and growing interest in its implementation.

3. Until now the synchromodality concept is largely defined in transportation terms and logistics service providers (LSPs) are its principal agents. Although in the original proposal of Verweij (2011) both the LSPs and the shippers were involved in its implementation, later research has generally focused on LSPs only. In the latter case, shippers simply leave the freight mode choice to the LSPs, thus making a 'mode-free' booking.

4. The most quoted benefit of synchromodality lies in improved sustainability, both in economic and environmental terms. This accrues partly from increased probability of freight modal shift but also from greater flexibility in the real-time planning of transportation modes to adapt to variable demand.

5. The relationship between synchromodality and the management of supply chain processes, particularly the management of inventory, has not yet been discussed in detail in the literature. 


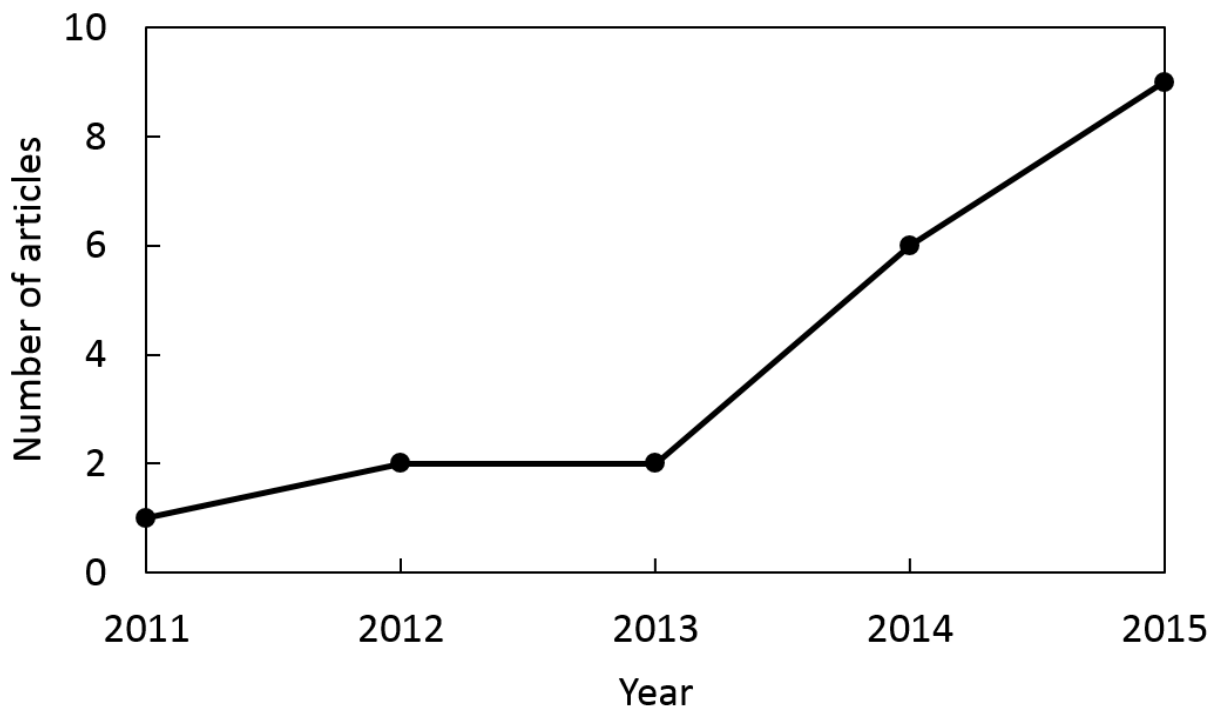

Figure 3: The number of published articles on synchromodality 


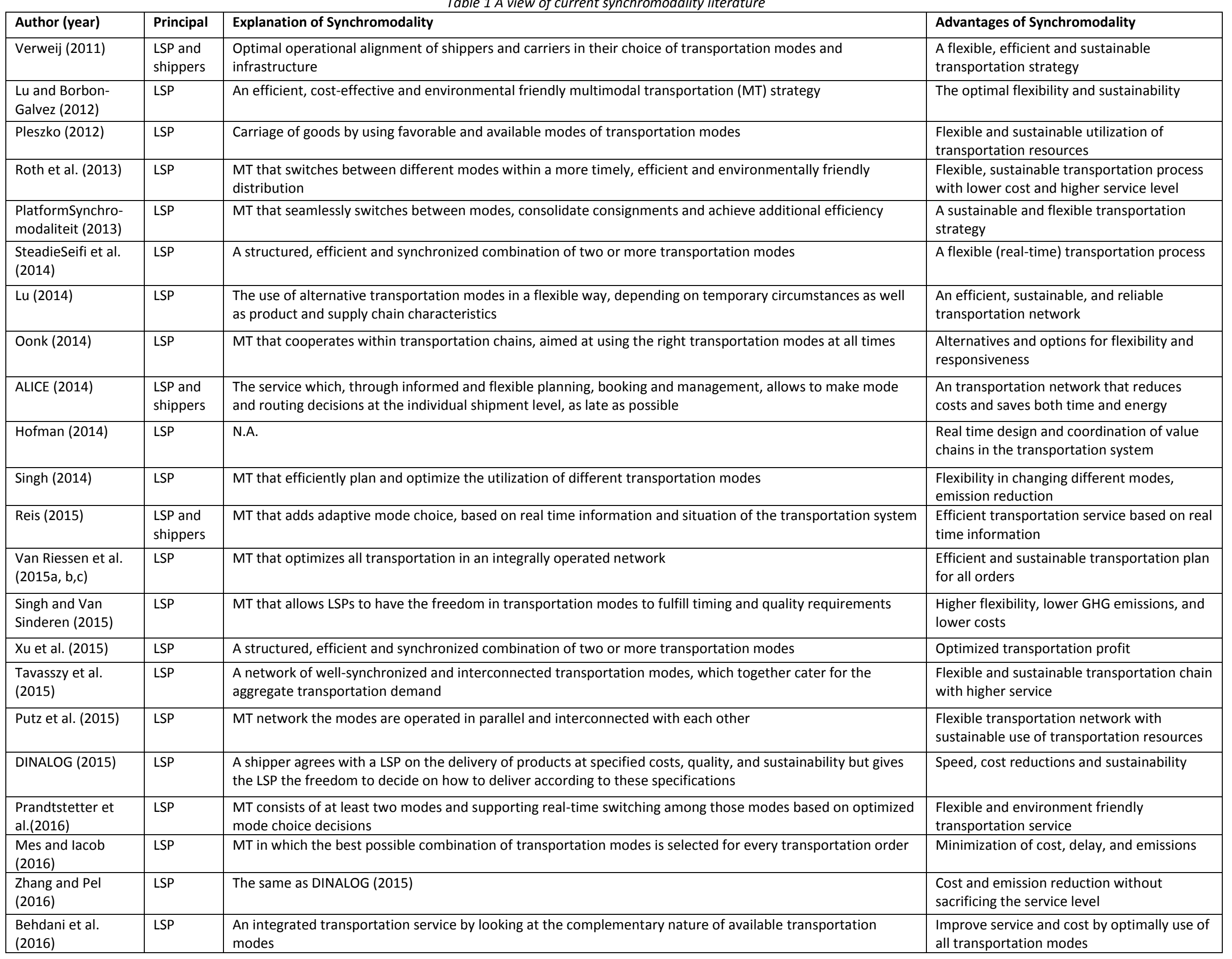




\subsection{Synchromodality from a supply chain perspective}

While synchromodality adds the synchronization of the transportation modes to the conventional intermodality problem, the SSCP concept further extends synchromodality from being a transportation concept to a principle impacting more widely on supply chain decision-making.

Figure 4 illustrates intermodal transportation, synchromodal transportation and SSCP. Synchromodal transportation (Figure 4b) extends the one-dimensional freight pathway of intermodal transportation (Figure 4a) to a two-dimensional freight flow network involving simultaneous usage of different modal pathways in the same corridor. One of these pathways could be intermodal transportation. In SSCP, the transportation decision, after all, is only one building block in the overall optimization of a supply chain (see Figure 4c). The meaning of 'synchro' in synchromodality needs to be broadened from the synchronization (and scheduling) of the different transportation modes towards the synchronization (and scheduling) of transportation with other supply chain activities such as inventory management and the setting of service levels.

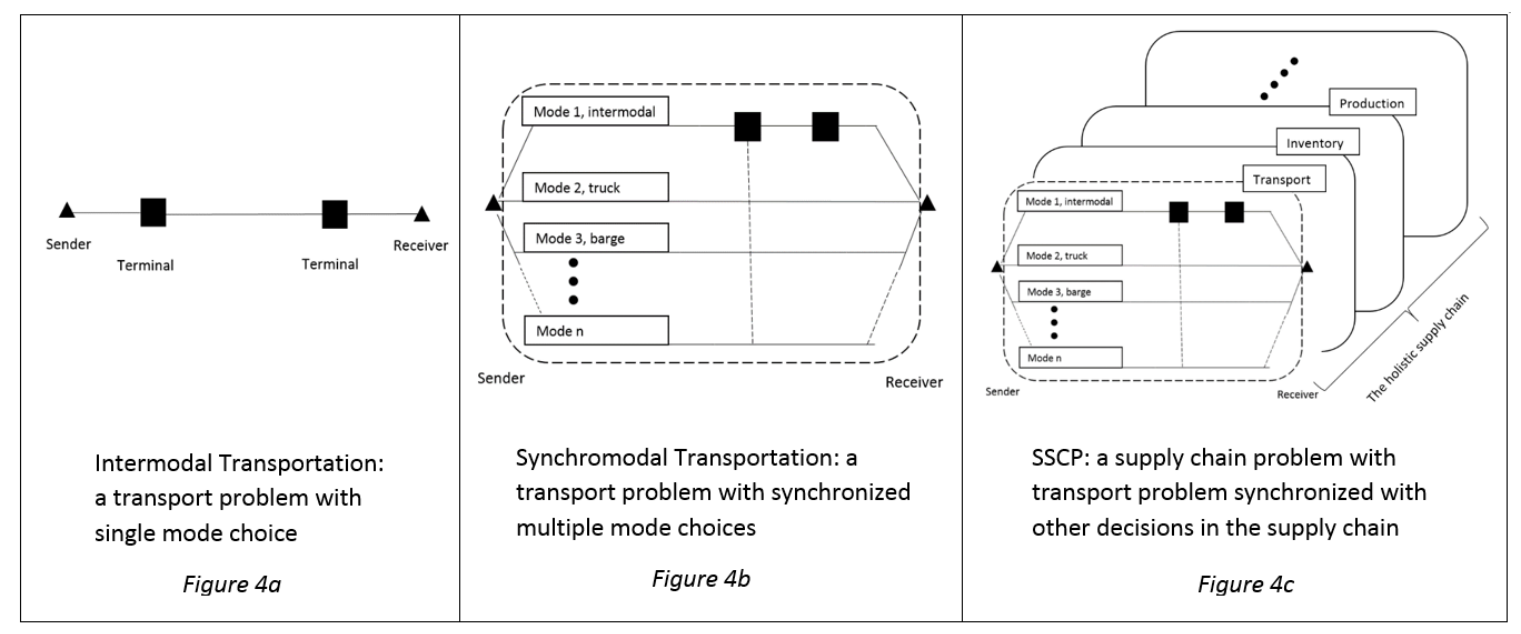

Figure 4: A comparison between intermodality, synchromodality, and SSCP

In Groothedde et al. (2005) the synchronized parallel usage of direct trucking and intermodal transportation is discussed, thereby operationalizing synchromodality from an LSP's perspective. We suggest that, when a shipper wants to implement synchromodality, it needs to evaluate the transportation decisions from an overall supply chain perspective. For example, intermodal transportation may lack the flexibility to vary carrying capacity and may result in unnecessarily high inventory in the supply chain. It also requires a long lead time and therefore may not satisfy demand surges at short notice. As a consequence more sophisticated supply chain models in which transportation decisions are synchronized with other decisions within the supply chain, such as dynamic inventory management and service level controls, are required. 
The SSCP approach entails a more holistic view of the supply chain incentives that the shippers may have when they make synchromodal decisions, instead of simply outsourcing the transportation decision to the LSPs and leaving them to optimize the transportation operation. Even where shippers contract out their transportation, they can still exert control over the choice of mode and carrier through a 'control tower'. According to a survey by Boston Consulting Group (2015) with 40 international corporations, up to $59 \%$ of the surveyed shippers now manage transportation in-house, as they believe that they can have a 'better control of their service levels'. A broader third-party logistics study by CapGemini (2016) reports that although shippers in general continue to rely heavily on LSPs, about $35 \%$ of them are insourcing more control of their logistics activities. The reasons offered for this include misalignment of logistics goals and objectives, lack of transparency and effective communications, lack of IT capabilities among LSPs, etc.

Naturally, LSPs and shippers have different business models and operational strategies. The LSPS that explore synchromodality as a business model tend only to consider how it affects their own transportation operations. Shippers, on the other hand, are also interested in its wider impacts on endogenous elements in the production and distribution systems, such as inventories and production schedules. As a consequence the shipper-based, supply chain perspective on synchromodality is much broader than that of an LSP. The differences are summarized in Table 2.

Table 2: Different perspectives of synchromodality

\begin{tabular}{|c|c|c|}
\hline & Transportation perspective & Supply chain perspective \\
\hline Organization & Mainly LSPs & Shippers \\
\hline Scope & A transportation network & End-to-end supply chain \\
\hline Complexity & $\begin{array}{l}\text { Network extent and intermodal } \\
\text { connections }\end{array}$ & Supply chain trade-offs and synergies \\
\hline Objective & $\begin{array}{l}\text { A flexible transportation network, where } \\
\text { all transportation modes are efficiently } \\
\text { utilized and modal shift facilitated }\end{array}$ & $\begin{array}{l}\text { A synchronized supply chain, where } \\
\text { inventory-transportation trade-offs } \\
\text { are recalibrated to exploit multimodal } \\
\text { flexibility }\end{array}$ \\
\hline $\begin{array}{l}\text { Quantitative re- } \\
\text { search method }\end{array}$ & $\begin{array}{l}\text { Transportation planning algorithms, e.g., } \\
\text { the multi-objective k-shortest path } \\
\text { problem used by Mes and lacob (2016) }\end{array}$ & $\begin{array}{l}\text { Supply chain optimization, e.g., } \\
\text { models integrating transportation and } \\
\text { inventory decisions }\end{array}$ \\
\hline
\end{tabular}

Synchromodality from a Supply Chain Perspective is defined as:

A multimodal strategy that incorporates the flexible choice of freight transportation modes into shippers' management of supply chain processes.

This perspective redefines the modal choice decision and encourages shippers to re-examine their transportation strategies from a holistic supply chain perspective. Synchromodality requires the active involvement of shippers in modal split decisions to align mode choice with production and inventory 
management and to accommodate transportation changes into their end-to-end supply chains. Shipper's responsibility and effort are acknowledged, in order to improve the performance of the supply chain.

\subsection{SSCP and the total logistics costs approach}

Whereas synchromodality allows for parallel usage of different transportation modes from the origin to the destination, SSCP aims to determine the optimal allocation of freight between the transportation modes that optimizes the total supply chain performance. This is closely related to the literature applying a total logistics costs (TLC) approach to optimize freight modal choice and inventory decisions, which is already extensively discussed in the literature. The general problem setting is proposed by Baumol and Vinod (1970), who develop a total logistics costs model (they define it an 'inventory-theoretic model') to analyze the trade-off between transportation and inventory costs. When a firm uses a slow rather than a fast transportation mode, it will increase the inventory holding costs.

Baumol and Vinod's TLC model is extended in various ways, e.g., by considering demand variability (Das, 1974), inventory backorder costs (Constable and Whybark, 1978), capacity and service level constraints (Sheffi et al., 1988), production set-up costs (Blumenfeld et al., 1991), to multi-products with different value and transportation schedules (Speranza and Ukovich, 1994), in a multi-echelon inventory setting (Miller and Matta, 2003), in a transportation network allowing for freight consolidation in specific nodes in the network (De Jong and Ben-Akiva, 2007), lead time variability (Dullaert and Zamparini, 2013), etc. All these models aim to support firms' decisions in freight mode choice and inventory controls. Lloret-Battle and Combes (2013) and Combes and Tavasszy (2016) provide empirical justification of the inventory-theoretic model, and show that shippers significantly increase their freight mode decisions when incorporating inventory controls. We refer to Winston (1983), Min and Zhou (2002), Meixell and Norbis (2008), and Tavasszy et al. (2012) as extensive literature reviews on studies applying a total logistics costs approach.

Although there is a substantial body of literature on the application of the TLC approach, Groothedde et al. (2005) is one of the few studies that incorporates simultaneous usage of more than one transportation mode. In their model, the more stable part of the freight demand that can be more accurately predicted is allocated to an intermodal transportation service, while the more variable part is delivered by truck. Our research relaxes the limiting assumption made by Groothedde et al. (2005) that only stable, predictable flows are shifted to intermodal services. This should permit greater use of slower, greener intermodal services. Rather than restrict the use of these services to a particular category of demand, our model allocates freight in relation to TLC measured on a supply chain basis from the shipper's perspective allowing for dynamic inventory management and stochastic customer demand. Application of our model should therefore enable shippers to exploit synchromodality more fully and increase their usage of intermodal transportation. 


\section{A case study of SSCP}

In this section we present the findings of a real world research project, which examined the potential for increasing a large shipper's relative use of intermodal rail transportation by using SSCP. In order to preserve commercial confidentiality, it is not possible to reveal the company data used in this case study. Instead, the values declared for key parameters are realistic industry-level figures and not specific to any particular company. We show that by applying SSCP with industry level parameters, the company can increase its modal split of currently $30 \%$ of the freight volume shipped via intermodal rail in one specific corridor, to as much as $70 \%$ consigned on intermodal rail transportation in the same corridor. The environmental impact of this modal shift involves a reduction of $\mathrm{CO}_{2}$ emissions with $30 \%$ on this specific transportation lane.

Whereas the SSCP concept involves the integration of the flexible choice of freight mode into a shipper's supply chain strategy, including transportation, inventory, production, etc., in this case study we restrict to the modal split between two transportation modes, intermodal rail and truck, and focus on the essential transportation-inventory trade-off in managing supply chains. As flexible mode shifts are practical infeasible in this corridor, we did not take that attribute of synchromodality into account.

\subsection{Current baseline situation}

A shipper operates a distribution center $(D)$ in Western Europe, which is replenished from its plant $(P)$. The replenishment orders are measured in the standard unit of Full Container Load (FCL). A FCL accounts for the volume loaded in a standard 45-foot container. Replenishment order varies over time, and we assume that the replenishment order follows a gamma distribution and normalize its mean to be 100 . Note, because the objective of the firm is to increase the ratio of intermodal rail transportation, the normalization of the numbers will not affect the outcome. Due to the nature of the products, replenishment orders are highly volatile. Standard deviation is assumed to be 60 , indicating that the coefficient of variation of the freight volume is $60 \%$.

The road corridor connecting plant $P$ and distribution center $D$ is 500 kilometers. There is no direct rail connection between $P$ and $D$, but there is an intermodal rail corridor that consists of a rail leg of 500 kilometers and a road leg of 50 kilometers. The distance of this corridor is larger than 300 kilometers, which is long enough to use intermodal rail transportation as suggested by European Commission (2011). Intermodal rail transportation has a lower cost than road transportation per unit of delivery. However, despite its cost advantage, intermodal rail transportation has inflexibilities in delivery quantity and schedule: Because of the rigidity of the train schedule and its transportation capacity, intermodal rail transportation requires shippers to commit stable volumes over a long planning horizon. This stability is essential to make intermodal rail economically viable. The shipper needs to decide the constant volume consigned on intermodal rail transportation on a daily base. 
For the shipper it is not feasible to put all its freight orders on intermodal rail. Given the rigidity of rail transportation, such a level strategy with constant deliveries equal to the average demand each period, leads to an unstable inventory process which increases in variability over time (Boute et al. (2007), Boute and Van Mieghem (2015)). To limit the resulting inventory increase at the distribution center $D$, the shipper therefore only consigns the stable part of its freight volumes onto intermodal rail, and the volatile part of its freight volumes on trucks to satisfy the service levels. The stable part coincides with the lower bound of the demand volumes (see Figure 5). The share of freight moved by intermodal rail is thus calculated as:

The share of intermodal rail transport $=\frac{\text { minimum replenishment order }}{\text { mean replenishment order }}$

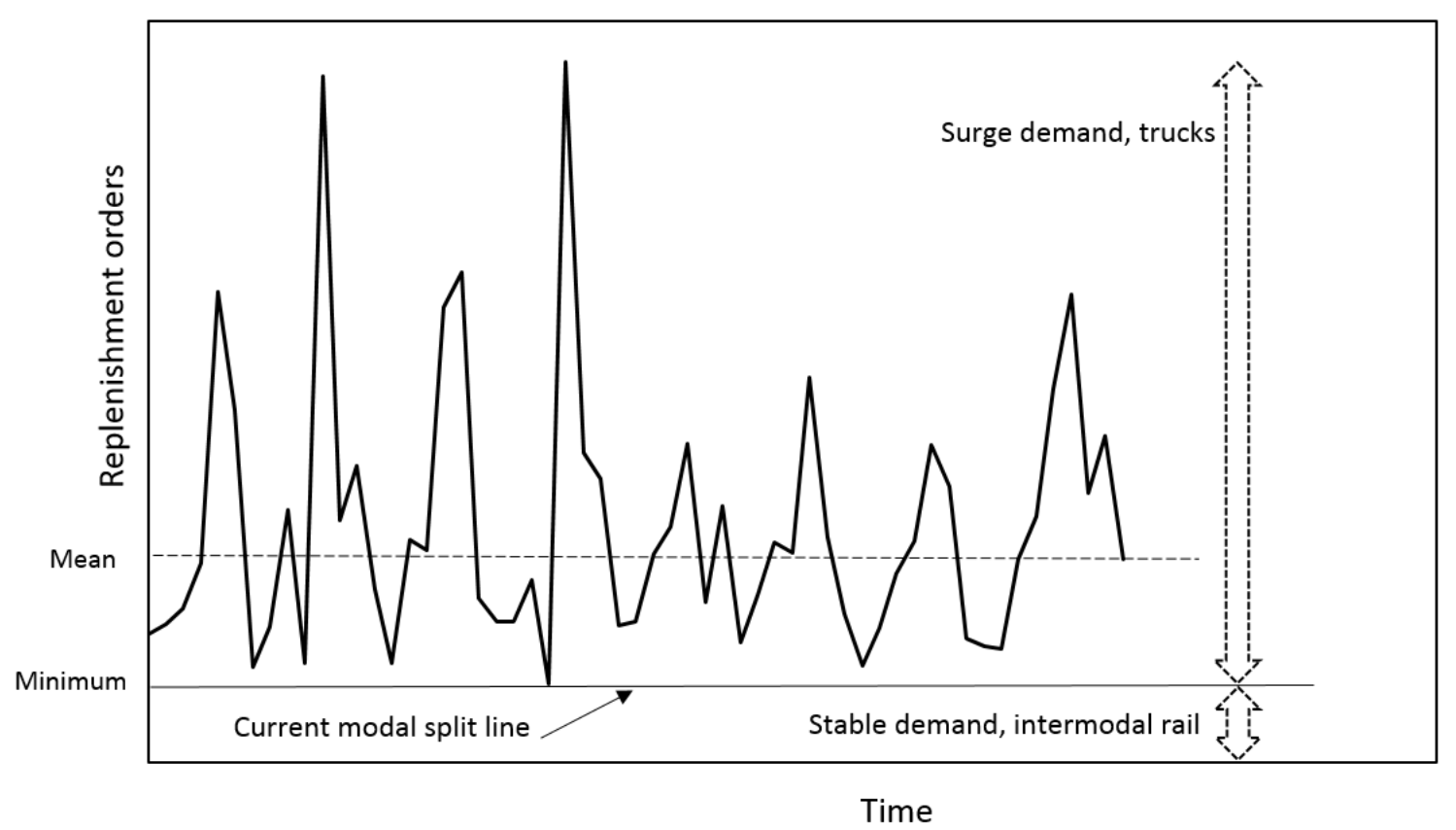

Figure 5: The current usage of intermodal rail transportation

This approach is standard practice in industry (see, e.g., Groothedde et al. (2005)). However, when the replenishment orders are volatile, as in Figure 5, the stable part of the replenishment order is often minimal, which discourages a high usage of intermodal rail transportation. In our case study, the ratio of intermodal rail is about $30 \%$ of total freight movement on the particular route, i.e., $\frac{\text { minimum replenishment order }}{\text { mean replenishment order }}=0.3$, which indicates that as much as $70 \%$ of total volume still needs to be transported via road transportation. We acknowledge that in practice, the firm can move the current modal split line slightly above to gain more opportunities in intermodal rail transportation. Nevertheless, the intermodal rail ratio remains at roughly $30 \%$. 
Obviously this ratio varies widely between companies. The chemical industry for example traditionally faces a more stable demand, where the ratio in expression (1) is much higher. This is a major reason why the chemical industry has a much higher utilization of intermodal rail, e.g., BASF (2012).

\subsection{Increasing the share of intermodal rail transportation by applying SSCP}

The operational inflexibility of intermodal rail transportation, in terms of volume, delivery frequency and schedule, etc., does not fit the volatile nature of freight volume, and hence discourages a high ratio of modal split in intermodal rail transportation in the current baseline situation. The SSCP approach allows firms to have more flexibility by exploiting a flexible usage of different transportation modes, as well as capturing the wider trade-off inside the supply chain.

The current modal split ratio as described above is based on the assumption learnt from standard industry practice (Groothedde et al., 2005) that only the stable part of the replenishment order (defined by its minimum) is transported by intermodal rail, because managers tend to perceive that a straight shift from trucks to trains and barges is likely to have a negative impact on the supply chain, especially an increase of inventory in both ends of the journey. No account is taken of shipper's total logistics costs. Instead it is presumed that the use of intermodal services will incur higher inventory costs thereby discouraging the use of these services by all but stable, predictable flows.

We argue that a proportion of the less stable flows can also be transported by intermodal rail, if the modal split ratio is optimized with respect to the shipper's transportation and inventory costs. When the transportation cost reduction resulting from the increased share of intermodal rail exceeds the corresponding inventory costs increase, it makes sense to do so from a total supply chain cost perspective. SSCP therefore looks at the synchromodal decision from the total supply chain perspective, rather than only looking at it in transportation terms.

\section{Notation:}

$\begin{array}{ll}t & \text { Time period index, } t=1 \ldots T \\ c^{T R} & \text { Unit transportation cost via truck transportation } \\ c^{R A} & \text { Unit transportation cost via intermodal rail transportation } \\ e^{T R} & \text { Unit carbon emission from truck transportation } \\ e^{R A} & \text { Unit carbon emission from intermodal rail transportation } \\ l^{T R} & \text { Lead time of truck transportation } \\ l^{R A} & \text { Lead time of intermodal rail } \\ h & \text { Unit inventory holding cost } \\ k & \text { Unit cost of capital }\end{array}$




$\begin{array}{ll}b & \text { Unit inventory backorder cost } \\ \xi_{t} & \text { Demand in period } t, \text { following an non-negative i.i.d. distribution } \\ \mu & \text { Mean of demand } \xi_{t} \\ x_{t} & \text { Starting inventory position at the beginning of period } t \\ Q & \text { The constant delivery quantity via intermodal rail transportation, decision variable } \\ S & \text { The order-up-to level of the inventory policy, decision variable } \\ z_{t} & \text { The delivery quantity via truck transportation placed in period } t \\ C_{t} & \text { The total logistics cost including transportation and inventory in period } t \\ \bar{C} & \text { The average of } C_{t} \text {. This is the objective value to be minimized } \\ \bar{e} & \text { The average emissions per period }\end{array}$

Model

A firm ships its replenishment orders from $P$ to $D$ by a simultaneous usage of two transportation modes: intermodal rail, and truck. From a modelling point of view, "intermodal rail" can be read as "rail transportation" and this change will not affect the setting and analysis of the model. We use "intermodal rail" because in our specific case study, the connection is an intermodal rail instead of a direct train. Similar to the standard approach described in Groothedde et al. (2005), our model assumes that intermodal rail always delivers a constant shipment quantity $Q$ from $P$ to $D$ for every period. This quantity $Q$ is a decision variable. Because a constant quantity is shipped and delivered during every period, the lead time of intermodal rail transportation can be ignored (Baumol and Vinod, 1970). However, the pipeline inventory incurs a financial cost, i.e., the opportunity cost of the capital invested in inventory within the transport system.

Another decision is the volume simultaneously shipped by truck $z_{t}$ in period $t$ linked to the inventory replenishment policy. The current mainstream freight transportation models linked to inventory management are formed on the basis of the classical Economic Order Quantity (EOQ) model (e.g., Combes, (2013)). However, EOQ models are built on a strong assumption that the demand of the model is deterministic, i.e., the demand remains the same in all periods. In order to analyze the volatile demand, we implement the base-stock inventory replenishment policy as suggested widely in the inventory literature, e.g., Karlin and Scarf (1958), Zipkin (2000), and Porteus (2002).

The base-stock policy works as follows: At the beginning of $t$ the firm has $x_{t}$ inventory in $\mathrm{D}$, then the truck transportation delivers $z_{t-l^{T R}}$ (Truck transportation has a lead time of $l^{T R}$ periods so that the replenishment orders from $t-l^{T R}$ period arrives in period t.) and intermodal rail transportation delivers $Q$, and the firm thus has an inventory level of $x_{t}+z_{t-l^{T R}}+Q$. If this level is below the base-stock level $S$, then $z_{t}=\left(S-Q-z_{t-l^{T R}}-x_{t}\right)$ units are to be replenished and delivered via truck. Otherwise no delivery is made. Hence, $z_{t}=\left(S-Q-z_{t-l^{T R}}-x_{t}\right)^{+}$, with ()$^{+}$defined as the positive part of a real-valued function 
in the brackets. After that, demand $\xi_{t}$ is realized. Note, $\xi_{t}$ is a non-deterministic variable. Because of the uncertainty in $\xi_{t}$, at the end of every period two mismatch-scenarios could happen: 1) If the on-hand inventory in $D$, denoted as $x_{t}+z_{t-l^{T R}}+Q$, is larger than $\xi_{t}$, the remaining inventory will be stored to the next period at a unit holding cost $h .2$ ) If the on-hand inventory is less than $\xi_{t}$, the unmet demand will be back-ordered to the next period with a unit penalty cost $b$. Denote $c^{R A}$ the unit transportation cost with intermodal rail and $c^{T R}$ the unit transportation cost with truck, the total costs in period $t$ is then:

$$
\begin{gathered}
C_{t}=c^{R A} Q+c^{T R} z_{t-l^{T R}}+h\left(x_{t}+Q+z_{t-l^{T R}}-\xi_{t}\right)^{+}+b\left(\xi_{t}-x_{t}-Q-z_{t-l^{T R}}\right)^{+}+k\left(l^{R A} Q+\right. \\
\left.z_{t-1}+\cdots+z_{t-l^{T R}}\right)
\end{gathered}
$$

where $c^{R A} Q$ represents the transportation cost of the freight volume received by intermodal rail, $c^{T R} Z_{t-l^{T R}}$ the transportation cost of the volume received by truck, $h\left(x_{t}+Q+z_{t-l^{T R}}-\xi_{t}\right)^{+}$the inventory holding cost in period $t, b\left(\xi_{t}-x_{t}-Q-z_{t-l^{T R}}\right)^{+}$the inventory backorder cost which is incurred in case the demand exceeds the total supply, and $k\left(l^{R A} Q+z_{t-1}+\cdots+z_{t-l^{T R}}\right)$ the cost of capital linked to the inpipeline inventory on both transportation modes at a rate of $k$. Although we acknowledge that the cost structure of an intermodal rail operator is typically lumpy (we refer to European Intermodal Association (2012) for the detailed cost structure of rail operation), we use a linear approximation because the cost structure for a shipper, i.e., the transportation cost paid by the shipper to the carrier, is close to a linear function.

The decision variables are $Q$ and $S$ and the objective is to minimize the average total logistics costs per period, including transportation (intermodal rail + truck) and inventory mismatch (holding + backorder) costs:

$$
\bar{C}=\frac{1}{T} \sum_{t=1}^{T} C_{t}
$$

\section{Parameters}

The inventory holding cost from the firm's perspective does not only consist of warehouse storage and handling cost, but also includes the cost of capital linked to the inventory. It is usually assumed that, the annual rate of cost of capital is $10 \%$ and the annual inventory holding cost of a product is equivalent to $25 \%$ of its value. The average value of the cargo in a FCL is assumed to be 100,000 EUR. The average cost of capital per day: $k=100,000 \times \frac{10 \%}{365}=27$, and the average inventory holding cost per FCL per day is therefore calculated as: $h=100,000 \times \frac{25 \%}{365}=68$. The inventory backorder penalty cost $b$ can be calculated indirectly via the customer service level, which is set to be $95 \%$ in the industry. In a base-stock inventory setting, the customer service level is given by the critical fractile $b /(b+h)$ (Zipkin, (2000), page 215). As a result, we obtain $b=1292$. To transport one FCL from $P$ to $D$ via road transportation costs 600 
EUR, i.e., $c^{T R}=600$, and to transport the same $\mathrm{FCL}$ via intermodal rail costs $c^{R A}=550$. The lead time of road transportation is one day, i.e., $l^{T R}=1$, and the lead time of intermodal rail is two days, i.e., $l^{R A}=2$. The following table summarizes the parameters values:

\begin{tabular}{|c|l|l|l|}
\hline Parameter & Description & Value & Unit \\
\hline$\mu$ & Mean of demand & 100 & Full container load (FCL) \\
\hline$\sigma$ & Standard deviation of demand & 60 & $\mathrm{FCL}$ \\
\hline$c^{T R}$ & Unit transportation cost by truck & 600 & EUR per FCL \\
\hline$c^{R A}$ & Unit transportation cost by intermodal rail & 550 & EUR per FCL \\
\hline$l^{T R}$ & Lead time of truck & 1 & Day \\
\hline$l^{R A}$ & Lead time of intermodal rail & 2 & Day \\
\hline$h$ & Unit inventory holding cost per period & 68 & EUR per FCL per day \\
\hline$k$ & Unit cost of capital per period & 27 & EUR per FCL per day \\
\hline$b$ & Unit inventory backorder cost per period & 1292 & EUR per FCL per day \\
\hline
\end{tabular}

\section{Results}

Although the problem structure is straightforward, the model is unfortunately analytically intractable. The characterization of the inventory process as a result of the dual sourcing inventory policy (a simultaneous usage of both transportation modes) makes it impossible to solve the model analytically: because the intermodal rail transportation always delivers a constant quantity into the distribution center, it is possible that it delivers more than needed and shoots the inventory over the base stock control level, and this excessive inventory cannot be obtained in explicit form. We refer to Rosenshine and Obee (1976), Allon and Van Mieghem (2010), and Janakiraman et al. (2015) for more detailed analysis on the characterizations of the inventory process. To the best of our knowledge, Combes (2011) and Dong et al. (2017) are the only studies that solve similar transportation problems with inventory considerations. However, they both use an approximation approach and do not show the optimal solutions. Our simulation approach is straightforward and obtains optimal solutions.

We solve the model optimally via simulation-based optimization through a search for all possible combinations of $Q$ and $S$ over a simulation time horizon $T$. Because both $Q$ and $S$ are integers, the computing effort is moderate.

The ratio $Q / \mu$ represents the share of the intermodal rail transportation. As described in section 3.1 , the company currently operates with intermodal rail share of $30 \%$, given by expression (1). The firm wants to reduce the environmental impact by shifting more volume from trucks to intermodal rail (i.e., increasing the value of $Q$ ), without increasing its total supply chains costs. We examine how the expected total cost 
per period behaves as a function of the intermodal rail share, i.e., we observe how $\bar{C}$ changes when $Q$ varies from its lower-bound zero (intermodal rail share of $0 \%$ ) to its upper-bound ${ }^{2} \mu$ (100\% intermodal rail share), and depict the results in Figure 6. The solid curve represents $\bar{C}$, the expected total logistics cost per period, and the two dotted curves represent the breakdown of the total cost $\bar{C}$ into transportation and inventory costs. For confidentiality reasons the exact numbers in the $y$-axis are not reported. In fact, we are interested in increasing the share of intermodal rail transportation and the exact value of $\bar{C}$ is out of scope of this research. Figure 6 shows that as the intermodal rail share goes up, the total transportation cost goes down linearly, but inventory cost increases in a convex manner. Specifically, when the share of the intermodal rail approaches to $100 \%$ (point F), almost all volumes are transported via intermodal rail, the SSCP model loses all flexibility, resulting in excessive inventory holding costs. As a comparison, at point $E$ the firm has all volume transported via road and the inventory is minimized.

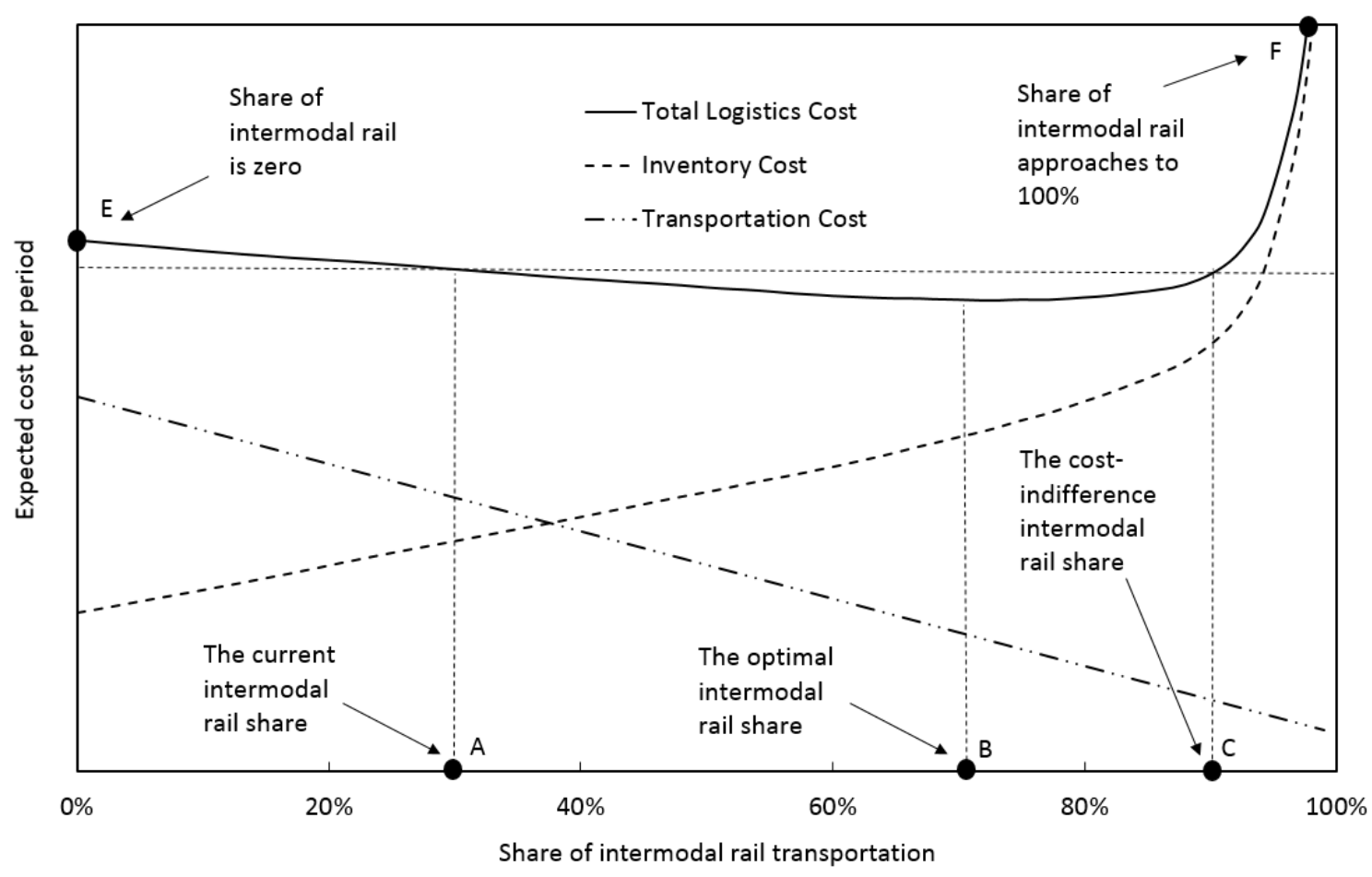

Figure 6: The expected total logistics cost per period and the share of intermodal rail by applying SSCP

In Figure 6, point A represents the current baseline situation, where about $30 \%$ of the volume is shipped by intermodal rail in the specific corridor from $P$ to $D$. When optimizing the modal split taking its impact on both transportation and inventory costs into account, we find that the total logistics cost can be further reduced by increasing the intermodal rail share to point $B$, where about $70 \%$ of the freight is shipped using intermodal rail on this specific intermodal rail corridor. This is a considerably higher modal share than in

\footnotetext{
${ }^{2} Q$ should not exceed $\mu$, otherwise the expected supply will be larger than the expected demand and the inventory will continuously build up.
} 
the current situation and is achieved without increasing the total logistics costs or reducing the customer service level. The move from point A to point B represents a redefinition of the synchromodality problem. Point A corresponds to the current practice of modal split as defined among others by Groothedde et al. (2005), in which the firm optimizes its mode choice as a pure transportation problem, and ships the stable predictable flow using intermodal rail and accommodates the unpredictable flow by direct trucking. Using this approach intermodal rail is assigned $30 \%$ of the freight. Moving the optimum to Point B effectively extends the boundary of the optimization problem into the supply chain realm. This can raise the intermodal rail share to $70 \%$ and shows how combined modelling transport and inventory variables allows synchromodality to achieve a more radical reallocation of freight between modes. Point $A$ can be considered a sub-optimal modal split based on transportation parameters only while point B a new global supply chain optimum.

From point $A$ to $B$, the firm obtains more transportation cost savings than extra inventory cost spending. From point $B$ to point $F$, the total logistics costs increase mainly due to an excessive increase in inventory holding costs. Point $\mathrm{C}$ is another interesting point. It represents a cost indifference point where the shipper remains at the same total logistics cost as its current situation, which is represented by point $A$. It indicates that the company could theoretically shift about $90 \%$ of its volume on a particular corridor onto intermodal rail, without compromising total logistics costs. Although this would indicate a major reduction in its environmental impact, this point will in practice be hard to attain because, without external stimulations from governmental policy or customer requirements, most firms will prioritize costs over emissions, and therefore stay at Point B. Still, Point C indicates that SSCP still offers further theoretical potential for environmental improvement at a supply chain level.

\subsection{The environmental impact of SSCP}

In this section we illustrate the environmental impact of SSCP by analyzing the corresponding savings in carbon dioxide $\left(\mathrm{CO}_{2}\right)$. We use the standard emission factor from European Environment Agency (2013): road transportation discharges in average 75 grams $\mathrm{CO}_{2}$ per tonne-kilometer (TKM), and rail transportation in average 21 grams $\mathrm{CO}_{2}$ per TKM. An FCL has an average payload of 24 tons so that to ship one FCL from $P$ to $D$ (distance of $500 \mathrm{kms}$ ) by road transportation emits on average $75 \times 24 \times 500=900,000$ grams, or 0.9 tons of $\mathrm{CO}_{2}$. We obtain $e^{T R}=0.9$. The intermodal journey has a rail trunk haul of about 500 kilometers with combined road feeder distances of 50 kilometers. To transport one $\mathrm{FCL}$ from $P$ to $D$ using the intermodal service emits $(75 \times 24 \times 50)+(21 \times 24 \times 500)=342,000$ grams, or 0.342 tons of $\mathrm{CO}_{2}$. We set $e^{R A}=0.342$. The average $\mathrm{CO}_{2}$ emission per period is then presented as:

$$
\bar{e}=\frac{1}{T} \sum_{t=1}^{T}\left(e^{R A} Q+e^{T R} Z_{t-l^{T R}}\right) .
$$


We do not consider GHG emissions caused by holding inventory. According to the World Economic Forum (2009), 'logistics buildings', comprising freight terminals, warehouses and depots, account for approximately $10 \%$ of total GHG emissions from logistics. The storage-related emissions would represent only a fraction of this $10 \%$ and be relatively fixed in the short- to medium-term regardless of the amount of inventory. A further reason for excluding inventory-related emissions from the analysis is that the products did not require temperature control. No refrigerant gases were emitted from this supply chain nor $\mathrm{CO}_{2}$ emissions associated with the cooling of warehousing or vehicles.

Because the unit emission from intermodal rail transportation is smaller than that from road transportation, i.e., $e^{R A}<e^{T R}$, to shift freight from road to intermodal rail transportation linearly decreases total emission $\bar{e}$. In theory the firm could minimize $\bar{e}$ in (4) by maximizing $Q$, i.e., consigning all freight to intermodal rail transportation. This is not a feasible solution, however, because the firm would then incur a significant increase in inventory costs as shown in point $\mathrm{F}$ in Figure 6.

We illustrate in Figure 7 the trade-off between total logistics costs and emissions when the firm increases its dependence on intermodal transportation. The current situation is denoted as Point $A$ as the basis for comparison ( $30 \%$ intermodal rail share). Point $E$ indicates total reliance on road transportation, which cause emissions and costs to be, respectively, $9 \%$ and $5 \%$ higher than at present. Point $\mathrm{F}$ corresponds to a scenario

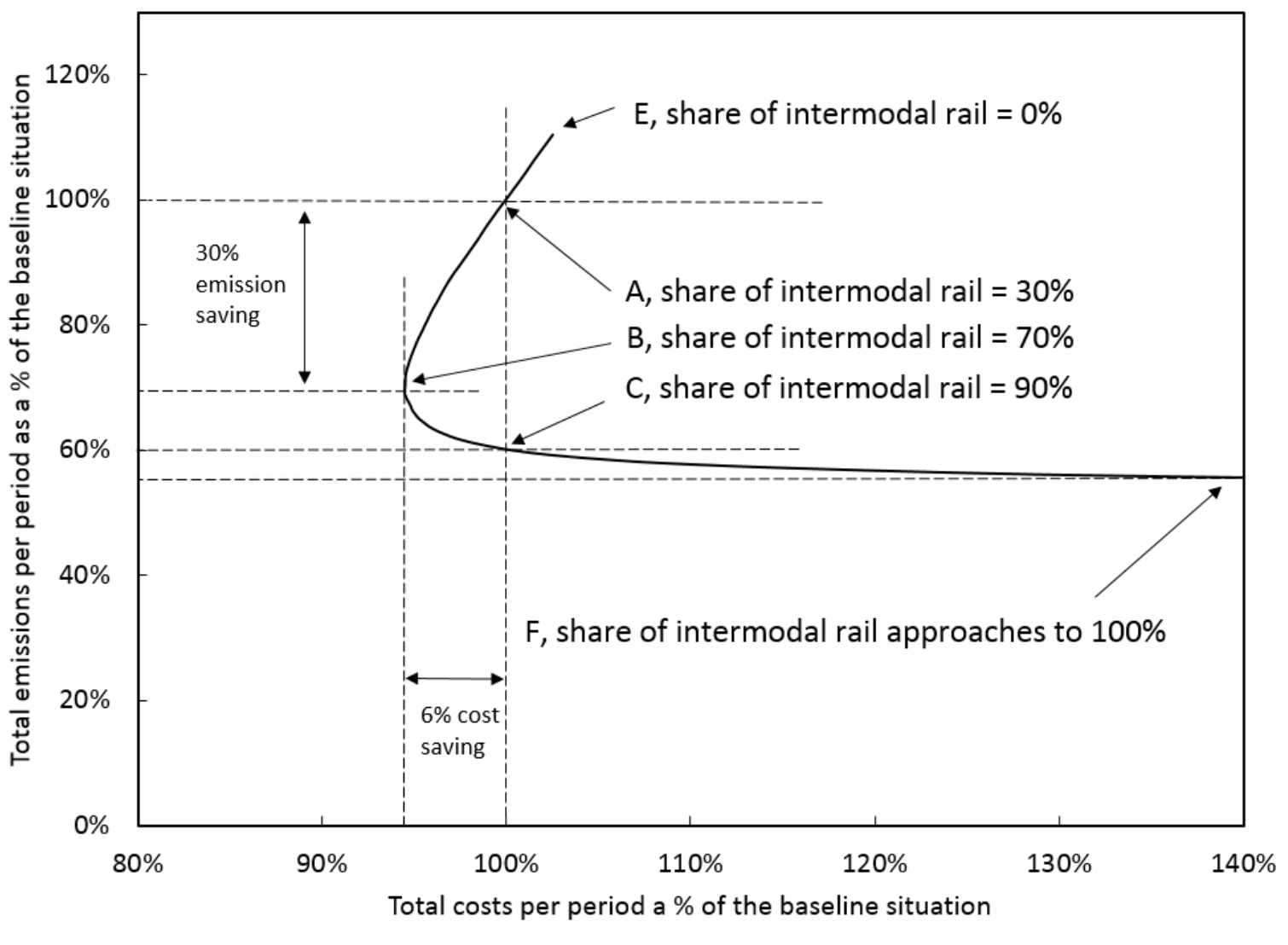

Figure 7: The costs and emissions trade-off curve 
in which the share in intermodal rail transportation approaches to $100 \%$. Although $\mathrm{F}$ is the 'greenest' solution in this plot with about $45 \% \mathrm{CO}_{2}$ emission savings compared to the baseline situation, it would inflate total logistics costs by roughly $40 \%$ as a result of higher inventories accumulating in the distribution center. Points $B$ and $C$ remain the same as in Figure 6 . At point $C$, the firm is able to save about $40 \%$ of total $\mathrm{CO}_{2}$ emission without incurring extra costs. The most realistic result of SSCP is point $\mathrm{B}$, where the firm could obtain logistics cost savings of about $6 \%$ as well as emissions savings of about $30 \%$, compared to the current situation at point $A$. This would represent a win-win option yielding economic and environmental benefit.

Hoen et al. (2013) have discussed a trade-off between cost and emissions. They find that 'intermodal transport, which is typically less carbon emitting, is more expensive (in terms of total logistic cost) than road transport for $63 \%$ of the customer lanes'. On the basis of this observation, they demonstrate that firms in general need to trade higher cost for an emission reduction. In contrast to their study, our model assumes that the greener intermodal alternative is also cheaper compared to road transportation (see, e.g., EUROSTAT(2015b); Floden and Williamsson (2015)). Greater use of intermodal transportation can therefore lead to both cost and emission reductions.

Currently the firm regards the choice of transportation mode as purely a transportation problem and hence stays at point A. The analysis indicates that by applying SSCP and optimizing modal choice at a supply chain rather than transportation level, the firm is able to further exploit both the economic and environmental benefits of intermodal rail transportation. From points $B$ to $F$, the firm would have to trade-off higher logistics costs for emission reductions. It would have to be incentivized to make such a trade-off by exogenous pressures, such as the imposition of a carbon tax, greater willingness of customers to pay for a lower carbon products or steep increases in fossil fuel prices.

The introduction of a carbon tax would encourage companies to shift freight to lower carbon modes. We have used our SSCP model to assess the impact on carbon emissions and logistics costs of setting carbon taxes at different levels.

Denoting $\beta$ as the carbon tax per ton, the firm needs to minimize the total costs of transportation, inventory, and carbon tax payments. The total costs per period in the presence of a carbon tax is then:

$$
\begin{array}{r}
\widehat{C_{t}}=c^{R A} Q+c^{T R} z_{t}+h\left(x_{t}+Q+z_{t-l^{T R}}-\xi_{t}\right)^{+}+b\left(\xi_{t}-x_{t}-Q-z_{t-l^{T R}}\right)^{+}+k\left(l^{R A} Q+z_{t-1}+\cdots+\right. \\
\left.z_{t-l^{T R}}\right)+\beta\left(e^{R A} Q+e^{T R} z_{t-l^{T R}}\right)
\end{array}
$$

The objective is to minimize the average of $\widehat{C_{t}}$. 
We follow Fahimnia et al. (2015) and set the value of $\beta$ to 0, 21, 42, 104 and 208 EUR $^{3}$ per ton. The resulting cost and emission trade-off curves are plotted in Figure 8.

The curve with $\beta=0$, i.e., no carbon tax, is equivalent to the single curve shown in Figure 7. However, now the benchmark is changed from point $A$ to $B$, because the impact of the carbon tax is evaluated against the optimum. When the value of $\beta$ increases, the trade-off curve moves to the right, indicating that the total costs are inflated by the addition of the carbon tax payments.

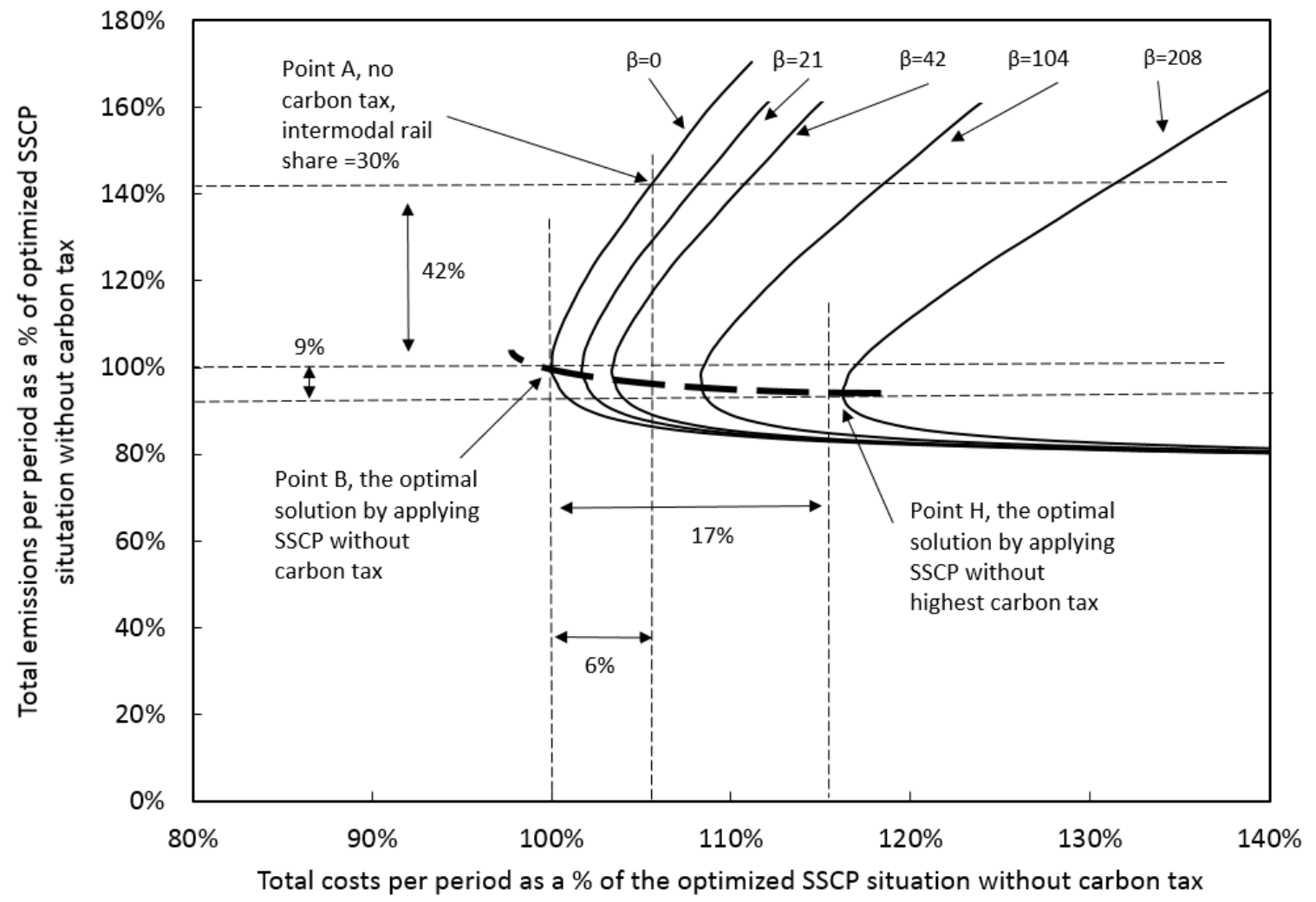

Figure 8: The costs and emissions trade-off curves with various carbon tax rate $b$

Point $\mathrm{B}$ in Figure 8 minimizes the average total costs $\left(\widehat{C}_{t}\right)$ when there is no carbon tax, and point $\mathrm{H}$ minimizes the total costs in the high carbon tax scenario of $\beta=208$ EUR per ton. In the high carbon tax scenario (point $\mathrm{H}$ ), the firm needs to trade $17 \%$ more total logistics cost for $9 \%$ less emissions. The cost increase is significantly larger than the emission reduction. In the absence of carbon tax, the use of SSCP allows the firm to optimize synchromodality in a broader supply chain context and obtain a $42 \%$ emission reduction (from A to B). However, when the supply chain of the firm is optimized by using SSCP (at point B), the incremental effect of a carbon tax on $\mathrm{CO}_{2}$ emission reductions is relatively small (only $9 \%$ represented by the move from $B$ to $H$ ). This suggests that the application of SSCP has the potential to substantially reduce

\footnotetext{
${ }^{3}$ The prices are originally quoted in USD in Fahimnia et al. (2015), and in our case study changed into EUR on the basis of the exchange rate on July, $1^{\text {st }}, 2015: 1$ USD $=0.9054$ EUR.
} 
$\mathrm{CO}_{2}$ emissions (from point $\mathrm{A}$ to $\mathrm{B}$ ) through optimization of the firm's 'internal' supply chain, whereas the 'external' interventions such as a carbon tax imposed by the government have only a minor incremental effect (moving from point $B$ to $H$ ), unless they are set at very high levels.

\subsection{Discussion}

Although this case study is analyzed on the basis of one set of industry-level parameters, several general insights can be found to support firms to reduce their environmental impact in freight movement. This case study shows that when current standard practice in industry is applied, with only the stable freight volumes transported by intermodal rail transportation (Groothedde et al., 2005), the share of intermodal rail is only moderate in case freight volumes are highly volatile. In order to increase the ratio in intermodal rail transportation, more flexibility can be introduced into the freight system by the following two aspects: i) the simultaneous usage of two transportation modes and, ii) the incorporation of the consequential transportation-inventory trade-off of the supply chain. These two aspects are the major features that we exploit in our SSCP concept discussed in Section 2. By following the SSCP approach, we show that it is possible to substantially reduce the total logistics costs and emissions at the same time.

We are aware that the case study does not fully reflect all attributes of SSCP as discussed in Section 2. Additionally, synchromodality allows to switch freely between transportation modes at particular times while a consignment is in transit (Verweij, 2011). In the case study presented in this paper, freight can practically not be shifted from road to intermodal rail during the journey, and vice versa. The lack of this flexibility might prevent our models from obtaining even higher costs savings and emission reductions. Nevertheless, even without this extra flexibility, our model has already demonstrated substantial improvement of the economic and environmental impact of the transportation system.

As this case study is specific to one shipper, it would clearly be unwise to apply the same modal split ratios for any practical scenarios. Whereas our results are illustrative for our company case study, they should not necessarily be representative of all industries as a whole. Depending on the company's freight volume volatility, unit transportation cost of intermodal rail versus road, and the cost of holding excess inventories, the optimal modal split ratio and its corresponding cost savings and emission reductions may be different.

We have subjected our results to a sensitivity analysis to test its robustness in different environments. In the current case study, intermodal rail costs about eight percent less per unit than trucking and captures about $70 \%$ of the freight. If the cost differential between both transport modes goes down, intermodal rail's share will be reduced. However, even if intermodal rail is only one percent cheaper than trucking, it retains around $60 \%$ of the traffic. We also tested the impact of the demand variability: when the demand is more volatile, trucking services that can handle variable delivery quantities will be favored. A numerical test shows that when the demand standard deviation increases from 60 to 200, the optimal modal share for 
intermodal rail drops from $70 \%$ to about $30 \%$. Although this is a substantial reduction, $30 \%$ is still significantly higher than the baseline share, where the lower-bound of the demand and the corresponding modal split were close to zero.

Finally, when the shipper applies our concept of SSCP, the LSP will have a different use of its transportation modes, and most likely more freight shipped via (intermodal) rail and less volume via road transportation. This is not per se negative for the LSP, even on the contrary. By increasing the volume in its rail freight transportation, it could enable a higher asset utilization of its rail infrastructure. However, that relies on many assumptions - a detailed quantification of its impact is therefore beyond the scope of this paper, but it is an interesting future research avenue.

\section{Conclusion}

Despite the efforts of policy-makers, particularly in Europe, to shift freight traffic from road to rail and waterborne transportation, the road-rail modal split has changed little over the past two decades. Innovations are urgently required in order to promote a substantial modal shift to alternative, moreenvironmental modes. This paper suggests that Synchromodality from a Supply Chain Perspective (SSCP) is such an innovation. It extends the original concept of synchromodality into the wider realm of supply chain management and shows how by adjusting their 'internal' inventory management shippers can more effectively exploit the greater modal flexibility which the 'external' synchromodality offers. A case study has been used to illustrate this approach and shown how a shipper can increase the modal share of intermodal rail and road from $30 \%$ to $70 \%$ in one intermodal rail corridor, resulting in a $6 \%$ total logistics cost saving and $30 \%$ emissions saving.

This study shows how the scope of the conventional multimodal transportation can be enlarged by including inventory management into the modelling of freight modal options. Further extensions of this work could incorporate other supply chain decisions relating production scheduling and service level constraints, or across the bounds of a single company's supply chain to a wider network involving more parties, e.g., under vertical collaboration, shippers and LSPs could coordinate their separate synchromodality decisions and achieve win-win solutions. The growth of horizontal collaboration among groups of companies is 'bundling' freight along particular corridors to more viable train loads (Sanchez-Rodrigues et al., 2015). If these companies collectively apply the SSCP principle, the potential impact of synchromodality on the freight modal split would be substantially reinforced. For example, if one shipper had a slump in demand, the others might still have sufficient volume to maintain adequate capacity utilization of the train. The aggregated demand of all the collaborating shippers drives a pooling effect and therefore reduces the risk to system viability posed by the variability of any single shipper's freight demand. This stabilization of total 
demand should further increase of intermodal rail's share and improve the environmental impact of freight transportation. 


\section{Reference}

ALICE, (Alliance for Logistics Innovation through Collaboration in Europe), 2014. Corridors, hubs and synchromodality. URL http://www.etp-logistics.eu/wp-content/uploads/2015/08/W26mayokopie.pdf.

Allon, G., Van Mieghem, J.A., 2010. Global dual sourcing: Tailored base-surge allocation to near-and offshore production. Management Science 56(1), 110-124.

BASF, 2012. We take a holistic view: Reducing emissions along the value chain. URL https://www.basf.com/us/en/company/sustainability/environment/energy-and-climateprotection/reducing-emission-along-the-value-chain.html. Accessed on 30 April, 2016.

Baumol, W.J., Vinod, H.D., 1970. An inventory theoretic model of freight transport demand. Management Science 16(7), 413-421.

Bayliss, B.T., Edwards, S.L., 1970. Industrial Demand for Transport. Ministry of Transport, HMSO, London.

Behdani, B., Fan, Y., Wiegmans, B., Zuidwijk, R., 2016. Multimodal schedule design for synchromodal freight transport systems. European Journal of Transport and Infrastructure Research 16(3), 424-444.

Blumenfeld, D.E., Burns, L.D., Daganzo, C.F., 1991. Synchronizing production and transportation schedules. Transportation Research Part B: Methodological 25(1), 23-37.

Bontekoning, Y.M., Macharis, C., Trip, J.J., 2004. Is a new applied transportation research field emerging? -A review of intermodal rail-truck freight transport literature. Transportation Research Part A: Policy and Practice 38(1), 1-34.

Boston Consulting Group, 2015. A Hard Road: Why CPG Companies Need a Strategic Approach to Transportation.

Boute, R., Disney, S., Lambrecht, M., Van Houdt, B., 2007. An integrated production and inventory model to dampen upstream demand variability in the supply chain. European Journal of Operational Research 178(1), 121-142.

Boute, R., Van Mieghem, J.A., 2015. Global dual sourcing and order smoothing: The impact of capacity and lead times. Management Science 61(9), 2080-2099.

CapGemini, 2016. The 2016 20th Annual Third Party Logistics Study.

Combes, F., 2013. Inventory theory and freight transport modelling, in: Tavasszy, L., De Jong, G. (Eds.), Modelling Freight Transport. Elsevier, pp. 89-115.

Combes, F., 2011. Inventory theory and mode choice in freight transport: the case of the simultaneous use of two transport modes on one shipper-receiver relationship, in: European Transport Conference 2011.

Combes, F., Tavasszy, L., 2016. Inventory theory, mode choice and network structure in freight transport. European Journal of Transport and Infrastructure Research 16(1), 38-52.

Constable, G.K., Whybark, D.C., 1978. The interaction of transportation and inventory decisions. Decision Sciences 9(4), 688-699. 
Crainic, T.G., Kim, K.H., 2007. Intermodal transportation, in: Barnhart, I.C., Laporte, G. (Eds.), Handbooks in Operations Research and Management Science. Elsevier, pp. 467-537.

Das, C., 1974. Choice of transport service: An inventory theoretic approach. The Logistics and Transportation Review 10(2), 181-187.

De Jong, G., 2013. Freight service valuation and elasticities, in: Tavasszy, L., De Jong, G. (Eds.), Modelling Freight Transport. pp. 201-227.

De Jong, G., Ben-Akiva, M., 2007. A micro-simulation model of shipment size and transport chain choice. Transportation Research Part B: Methodological 41(9), 950-965.

De Jong, G., Schroten, A., Van Essen, H., Otten, M., Bucci, P., 2010. Price sensitivity of European road freight transport - towards a better understanding of existing results. (A report for Transport \& Environment, Report 9012-1). Delft: Significance/CE Delft.

Dinalog, 2015. Synchromodal Transport. URL http://www.dinalog.nl/en/themes/synchromodal/. Accessed on 10 November, 2015.

Dong, C., Transchel, S., Hoberg, K., 2017. An inventory control model for modal split transport: A tailored base-surge approach. European Journal of Operational Research. Forthcoming.

Dullaert, W., Zamparini, L., 2013. The impact of lead time reliability in freight transport: A logistics assessment of transport economics findings. Transportation Research Part E: Logistics and Transportation Review 49(1), 190-200.

Eng-Larsson, F., Kohn, C., 2012. Modal shift for greener logistics - the shipper's perspective. International Journal of Physical Distribution \& Logistics Management 42(1), 36-59.

European Commission, 2015. Paris Agreement. URL https://ec.europa.eu/clima/policies/international/negotiations/paris/. Accessed on 14 December, 2016.

European Commission, 2011. White Paper on Transport: Roadmap to a Single European Transport Area Towards a Competitive and Resource Efficient Transport System. Brussels, Belgium.

European Commission, 1997. COM(97) 243 Final - Intermodality and intermodal freight transport in the European Union. Brussels, Belgium.

European Court of Auditors, 2016. Rail freight transport in the EU: still not on the right track. Luxembourg.

European Environment Agency, 2013. Specific CO2 emissions per tonne-km and per mode of transport in Europe, 1995-2011. URL http://www.eea.europa.eu/data-and-maps/figures/specific-co2-emissionsper-tonne-2. Accessed on 14 December, 2016.

European Intermodal Association, 2012. Intermodal Yearbook 2011-2012: Strategies, Statistics, Terminals and Players.

EUROSTAT, 2015a. Greenhouse gas emission statistics. URL http://ec.europa.eu/eurostat/statisticsexplained/index.php/Greenhouse_gas_emission_statistics. Accessed on 14 December, 2016.

EUROSTAT, 2015b. EU transport in figures - Statistical pocketbook 2015. 
Fahimnia, B., Sarkis, J., Choudhary, A., Eshragh, A., 2015. Tactical supply chain planning under a carbon tax policy scheme: A case study. International Journal of Production Economics 164, 206-215.

Floden, J., Williamsson, J., 2015. Business models for sustainable biofuel transport: the potential for intermodal transport. Journal of Cleaner Production 113(1), 426-437.

Gorris, T., Groen, T., Hofman, W., Janssen, R., Van Meijeren, J., Oonk, M., 2011. Implementatieroadmap Synchromodaliteit, TNO, Connekt and Dinalog commissioned by the Ministry of Infrastructure and Environment.

Gota, S., 2016. Freight transport and climate change, in: Transportation Research Board 96th Annual Meeting (Session 868). Washington DC.

Groothedde, B., Ruijgrok, C., Tavasszy, L.A., 2005. Towards collaborative, intermodal hub networks: A case study in the fast moving consumer goods market. Transportation Research Part E: Logistics and Transportation Review 41(6), 567-583.

Hoen, K., Tan, T., Fransoo, J., Van Houtum, G., 2013. Switching transport modes to meet voluntary carbon emission targets. Transportation Science 48(4), 592-608.

Hofman, W., 2014. Control tower architecture for multi- and synchromodal logistics with real time data, in: ILS2014, Breda.

Holguin-Veras, J., Paaswell, R., Perl, A., 2008. The role of government in fostering intermodal transport innovations perceived lessons obstacles in the United States, in: Konings, R., Priemus, H., Nijkamp, P. (Eds.), The Future of Intermodal Freight Transport: Operations, Design, and Policy. Edward Elgar Publishing, Cheltenham, UK, pp. 302-323.

Intergovernmental Panel on Climate Change (IPCC), 2014. Climate Change 2014: Synthesis report.

Janakiraman, G., Seshadri, S., Sheopuri, A., 2015. Analysis of tailored base-surge policies in dual sourcing inventory systems. Management Science, 61(7), 1547-1561.

Jeffs, V.P., Hills, P.J., 1990. Determinants of modal choice in freight transport - A case study. Transportation 17(1), 29-47.

Karlin, S., Scarf, H., 1958. Inventory models of the Arrow-Harris-Marschak type with time lag, in: Arrow, K.J., Karlin, S., Scarf, H. (Eds.), Studies in the Mathematical Theory of Inventory and Production. Stanford University Press, pp. 135-154.

Lloret-Battle, R., Combes, F., 2013. Estimation of an inventory theoretical model of mode choice in freight transport. Transportation Research Record: Journal of the Transportation Research Board 2378, 1321.

Lu, M., 2014. Synchromodality for enabling smart transport hubs, in: International Conference on Traffic and Transport Engineering, Belgrade 2014. pp. 875-880.

Lu, M., Borbon-Galvez, Y., 2012. Advanced logistics and supply chain management for intelligent and sustainable transport. 19th World Congress on ITS, Vienna.

Macharis, C., Bontekoning, Y., 2004. Opportunities for OR in intermodal freight transport research: A review. European Journal of operational research 153(2), 400-416. 
McGinnis, M.A., 1989. A comparative evaluation of freight transportation choice models. Transportation Journal 29(2), 36-46.

McKinnon, A., 2015. The role of government in promoting green logistics, in: McKinnon, A., Browne, A., Whiteing, M., Piecyk, M. (Eds.), Green Logistics. Kogan Page, London, pp. 341-360.

McKinnon, A., 2008. The potential of economic incentives to reduce CO2 emissions from goods transport, in: 1st International Transport Forum on Transport and Energy: The Challenge of Climate Change. pp. 28-30.

Meixell, M.J., Norbis, M., 2008. A review of the transportation mode choice and carrier selection literature. The International Journal of Logistics Management 19(2), 183-211.

Mes, M., lacob, M., 2016. Synchromodal transport planning at a logistics service provider, in: Zijm, H., Klumpp, M., Clausen, U., Hompel, M. (Eds.), Logistics and Supply Chain Innovation. Springer International Publishing, Switzerland, pp. 23-36.

Miller, T., Matta, R., 2003. Integrating production and transportation scheduling decisions between two geographically separated plants. Journal of Business Logistics 24(1), 111-146.

Min, H., Zhou, G., 2002. Supply chain modeling: past, present and future. Computers \& Industrial Engineering 43(1-2), 231-249.

OECD/ITF, 2015. ITF Transport Outlook 2015, URL http://www.oecd.org/publications/itf-transport-outlook2015-9789282107782-en.htm.

Oonk, M., 2014. Smart logistics corridors and the benefits of intelligent transport systems. Transport Research Arena 2014, Paris.

Platform Synchromodaliteit, 2013. Synchromodal Transport. URL www.synchromodaliteit.nl/wpcontent/uploads/2013/06/Presentation-synchromodal-transport.pptx. Accessed on 30 June, 2016.

Pleszko, J., 2012. Multi-variant configurations of supply chains in the context of synchromodal transport. LogForum 8(4), 287-295.

Porteus, E.L., 2002. Foundations of Stochastic Inventory Theory. Stanford University Press.

Prandtstetter, M., Putz, L., Pfoser, S., Haller, A., Lenz, G., Ponweiser, W., 2016. An Introduction to Synchromodal Networks in Austria. Proceedings FFH 2016, Wien, Austria, 2016, pp. 6.

Putz, L., Haider, C., Haller, A., Schauer, O., 2015. Identifying Key Enablers for Synchromodal Transport Chains in Central Europe. Proceedings of the WCTRS SIGA2 2015 Conference: The Port and Maritime Sector: Key Developments and Challenges, Antwerpen, Belgium, 2015.

Reis, V., 2015. Should we keep on renaming a+35-year-old baby? Journal of Transport Geography 46, 173179.

Reis, V., Meier, J.F., Pace, G., Palacin, R., 2013. Rail and multi-modal transport. Research in Transportation Economics 41(1), 17-30.

Rosenshine, M., Obee, D., 1976. Analysis of a standing order inventory system with emergency orders. Operations Research 24(6), 1143-1155. 
Roth, M., Klarmann, A., Franczyk, B., 2013. Future logistics - challenges, requirements and solutions for logistics networks. International Journal of Mechanical, Aerospace, Industrial, Mechatronic and Manufacturing Engineering 7(10), 898-903.

Sanchez-Rodrigues, V., Harris, I., Mason, R., 2015. Horizontal logistics collaboration for enhanced supply chain performance: An international retail perspective. Supply Chain Management: An International Journal 20(6), 631-647.

Schipper, L., Marie-Lilliu, C., Gorham, R., 2000. Flexing the link between transport and greenhouse gas emissions: A path for the World Bank.

Sheffi, Y., Eskandari, B., Koutsopoulos, H.N., 1988. Transportation mode choice based on total logistics costs. Journal of Business Logistics 9(2), 137-154.

Singh, P., 2014. Developing a service oriented IT platform for synchromodal transportation, in: On the Move to Meaningful Internet Systems: OTM 2014 Workshops. Springer Berlin Heidelberg, pp. 30-36.

Singh, P., Van Sinderen, M., 2015. Interoperability challenges for context-aware logistic services - The case of synchromodal Logistics. Proceedings of the Workshops of the 6th International IFIP Working Conference on Enterprise Interoperability, IWEI-WS 2015, 27 May 2015, Nines, France.

Speranza, M.G., Ukovich, W., 1994. Minimizing transportation and inventory costs for several products on a single link. Operations Research 42(5), 879-894.

SteadieSeifi, M., Dellaert, N.P., Nuijten, W., Van Woensel, T., Raoufi, R., 2014. Multimodal freight transportation planning: A literature review. European Journal of Operational Research 233(1), 1-15.

Tavasszy, L.A., Behdani, B., Konings, R., 2015. Intermodality and Synchromodality. Available at SSRN 2592888.

Tavasszy, L.A., Ruijgrok, K., Davydenko, I., 2012. Incorporating logistics in freight transport demand models: state-of-the-art and research opportunities. Transport Reviews 32(2), 203-219.

U.S. Environmental Protection Agency, 2014. Sources of Greenhouse Gas Emissions. URL https://www3.epa.gov/climatechange/ghgemissions/sources/electricity.html. Accessed on 30 April, 2016.

Van Riessen, B., Negenborn, R., Dekker, R., 2015a. Synchromodal container transportation: An overview of current topics and research opportunities, in: Computational Logistics. Springer International Publishing, Switzerland, pp. 386-397.

Van Riessen, B., Negenborn, R., Dekker, R., Lodewijks, G., 2015b. Service network design for an intermodal container network with flexible transit times and the possibility of using subcontracted transport. International Journal of Shipping and Transport Logistics 7(4), 457-478.

Van Riessen, B., Negenborn, R., Lodewijks, G., Dekker, R., 2015c. Impact and relevance of transit disturbances on planning in intermodal container networks using disturbance cost analysis. Maritime Economics \& Logistics 17(4), 440-463.

Verweij, K., 2011. Synchromodal transport: Thinking in hybrid cooperative networks, in: Van Der Sterre, P.J. (Ed.), Logistics Yearbook 2011. pp. 75-88.

Winebrake, J., Corbett, J., Falzarano, A., Hawker, J., Korfmacher, K., Ketha, S., Zilora, S., 2008. Assessing 
energy, environmental, and economic tradeoffs in intermodal freight transportation. Journal of the Air \& Waste Management Association 58(8), 1004-1013.

Winston, C., 1983. The demand for freight transportation: models and applications. Transportation Research Part A: General 17(6), 419-427.

Woodburn, A., 2003. A logistical perspective on the potential for modal shift of freight from road to rail in Great Britain. International Journal of Transport Management 1(4), 237-245.

World Economic Forum, 2009. Supply Chain Decarbonization, The Role of Logistics and Transport in Reducing Supply Chain Carbon Emissions.

Xu, Y., Cao, C., Jia, B., Zang, G., 2015. Model and algorithm for container allocation problem with random freight demands in synchromodal transportation. Mathematical Problems in Engineering 2015.

Zhang, M., Pel, A.J., 2016. Synchromodal hinterland freight transport: Model study for the port of Rotterdam. Journal of Transport Geography 52, 1-10.

Zipkin, P., 2000. Foundations of Inventory Management. McGraw-Hill NY. 